\title{
Perancangan Web Marketplace Toko Sepatu Akshara.co dengan Sistem Rekomendasi Menggunakan Perhitungan Algoritma Apriori
}

\author{
Dennise Gibran Manoppo, M Iwan Wahyudin, Winarsih" \\ Fakultas Teknik Komunikasi Informatika, Informatika, Universitas Nasional, Jakarta, Indonesia \\ Email: ${ }^{1}$ dennisgibranmanoppo@gmail.com, ${ }^{2}$ iwan_wyd@yahoo.com, 3, ${ }^{*}$ winarsih@civitas.unas.ac.id \\ Email Penulis Korespondensi: winarsih@ civitas.unas.ac.id
}

\begin{abstract}
Abstrak-Di zaman yang telah modern ini, sepatu merupakan kebutuhan penting bagi hampir semua kalangan, banyak sekali organisasi bisnis Online yang mempromosikan barangnya berdatangan dan tumbuh cukup signifikan, selain itu pemakai web dinamis di negara ini berkembang cukup signifikan tiap tahunnya. Mengakibatkan pelaku bisnis online saling bersaing untuk mengeksplorasi berbagai opsi teknik dalam hal periklanan untuk memberi ketertarikan kepada publik untuk membeli barang yang dijual.Untuk tetap eksis dalam perlombaan pasar usaha online di negara ini, satu contoh teknik yang promosi untuk menarik dan meningkatkan pembelian premium publik adalah dengan rekomendasi barang dagangan dalam bisnis Online.Sebab itu, dalam pengkajian ini, suatu bisnis dengan basis website elektronik akan dibuat yang dapat membantu organisasi bisnis Internet mengantisipasi premi pembeli dalam suatu hal dan kemudian meresepkannya untuk menarik lebih banyak pembeli yang datang. Bisnis berbasis web ini menggunakan cara Perhitungan Apriori untuk mendapatkan ketepatan yang lebih dalam ukuran penanganan informasi. Hasil yang diperoleh dari pengujian ini adalah pembuatan bisnis elektronik berbasis web dengan menerapkan teknik rekomendasi yang dihitung dengan algoritma apriori yang ditunjukkan pada "Akshara.co".
\end{abstract}

Kata Kunci: Rekomendasi; E-commerce; Apriori

\begin{abstract}
In this advanced period, shoes arsse an essential requirement for practically all circles, a great deal of Online business organizations are arising and filling quickly in Indonesia, in addition to the quantity of dynamic web clients in Indonesia is expanding quickly from one year to another. Making Online business organizations contend to explore different techniques as far as advertising to draw in more individuals to purchase the items they offer to get by in the online businss market rivalry in this country, one illustration of a promoting methodology to draw in and increment public premium buys is the execution of the merchandise proposal framework in Online business. Consequently, in this investigation, an electronic Web based business will be made that can help Internet business organizations anticipate purchaser premium in a thing and afterward prescribe it to draw in more purchasers who come. This Web based business utilizes the Apriori Calculation way to deal with get more exactness in the information handling measure. The outcomes acquired from that examination are the making electronic Web based business by executing the suggestion technique showed on the "Akshara.co" framework include.
\end{abstract}

Keywords: Data Mining; Algortms Apriori; Association Rules; Support; Confidience

\section{PENDAHULUAN}

Perkembangan pesat inovasi data dan kerangka kerja data pada masa sekarang membuat data dapat diperoleh secara efektif dan cepat dan tidak dapat dihindari hal ini terjadi di bidang bisnis hanya untuk mengatasi masalah pembelanja, kontes dilakukan oleh setiap organisasi untukk mendapatkan pemenuhan dan hasil yang ideal sebagai ditunjukkan oleh kebutuhan pelanggan. kebutuhan klien. Jadi pelaku bisnis harus mempertimbangkan prosedur dan lompatan ke depan yang dapat menjamin kelangsungan bisnis mereka. Kerangka data berguna bagi para pelaku bisnis sebagai media dalam membina bisnis mereka sebagai bantuan, media ini biasa disebut Web E-commerce yang digunakan untuk menawarkan, memberikan informasi rinci, dan harga barang.

Jika barang yang dijual di toko online bersifat banyak,enggan menutup kemungkinan setiap barang memiliki tolak ukur boolean dimana hal itu memberi petunjuk eksistensi barang tekait dalam sebuah list atau keranjang pembelian,dengan dasar daftar yang ada akan dipakai mencari barang yang terjual secara dengan rentan waktu yang sama. Berikutnya, informasi item ini dipakai dalam hal pemprosesan informasi dalam upaya mendapatkan barang yang mungkin akan keluar dan melampaui persyaratan dukungan terkecil dan kepercayaan terkecil dukungan dari kombinasi barang.nilai kepercayaan merupakan nilai pasti yang memberi gambaran kuatnya hubungan diantara barang dalam algoritma Apriori.

Nilai kepercayaan dapat didapkan jika gambaran frekuensi munculnya item telah didapat.Dalam pemakaian teknik data mining terdapat lebih dari 1 algoritma bisa dipakai untuk menggali informasi,diantaranya algoritma Frequent Pattern Growth, algoritma berbasis hash,algoritma apriori[1]-[3]. Dalam kasus ini, penulis memakai algoritma apriori. Penelitian ini mendeskripsikan teknik perekomendasian tampilan barang pada e-market menggunakan algoritma apriori berdasar presentase kepercayaan gabungan beberapa barang yang terjual pada kurun waktu tertentu yang bertujuan menjadi rekomendasi kepada owner atau pengelola e-maket dalam menetapkan atau memastikan akan menampilkan barang yang akan diluncurkan di etalasenya.

\section{METODOLOGI PENELITIAN}


Teknik yang diterapkan pada penelitian ini adalah metode Prototype.Pada era lampau prototipe mendeskripsikan desain sesuatu memakai kertas,yang mana pendisain menggambar alur kerangka yang terdiri masukan, keluaran, proses, dan basisdata,hal ini memakan banyak waktu dan memiliki kemungkinan terjadinya kekeliruan. Secara umum,apabila didapatkan dari desain kertas memungkinan banyak terjadi kekurangan.Di era saat ini penganalis masih banyak yang memakai prototipe. Metode pembuatan prototipe adalah pemprosesan berulang yaitu membangun komunikasi dan kerjasama baik diantara pengembang dan pengguna perangkat.[4]-[6]

Pressman berpendapat bawasannya pemakai beranggapan perangkat lunak adalah hal yang biasa, dan tidak memberi identifikasi rinci persyaratan masukan, proses, dan keluaran.Permasalahan serupa adalah, pengembang kurang dapat memastikan pengunaan algoritma yang tepat,dan harus menyesuaikan dengan sistem yang akan dipergunakan, atau langkah-langkah yang harus diambil dalam hubungan manusia denganmesin. Maka dalam hal tersebut cara yang efisien untuk dipakai adalah dengan cara prototipe[7], [8]. Berikut alur yang menggambarkan metode yang dipakai yang disajikan pada gambar 1 .

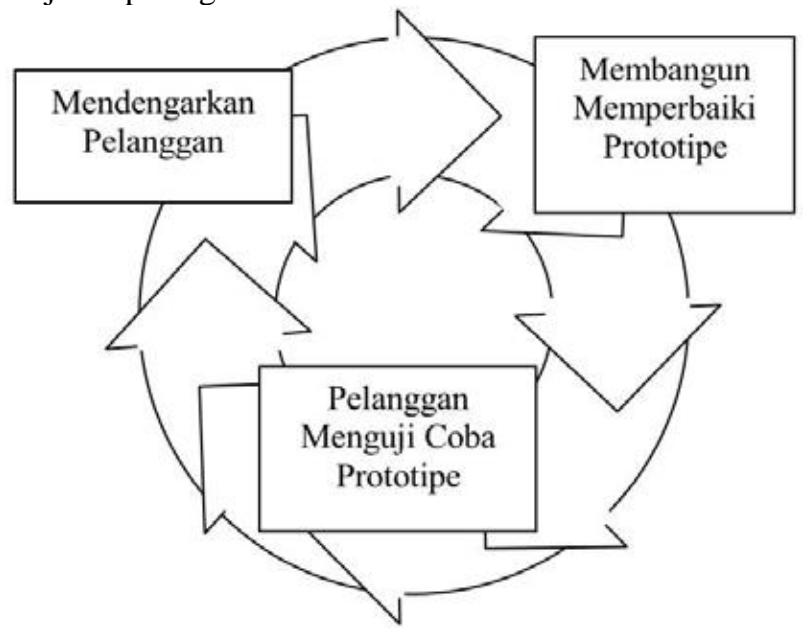

Gambar 1. Alur prototype

Desain penelitian cukup bagus dipakai untuk membuat sistem dan apabila suatu saat akan diteruskan kembali. Metode dimulai dari mendapatkan keperluan pemakai. Dalam hal tersebut pemakai sistem adalah klien. Kemudian menciptakan desain secara segera lalu setelah itu dibenahi yang pada akhirnya dapat dilanjutkan. Prototipe bukan suatu hasil jadi, melainkan sebuah desain untuk ditinjau melainkan sistem harus berkembang kedepannya.ketidakpstian dapat terjadi ketika membuat prototipe sesuai permintaan klien dan memberi keuntungan kepada pengembang dikarenkan lebih paham keinginan klien. Desain penelitian ini melewati 3 tahapan, termasuk pengumpulan keperluan, desain, dan peninjauan. Secara umum dapat dideskripsikan[9]-[12]:

1. Mengumpulkan keperluan

Pengembang beserta klien membahas dan mencari konklusi perancangan sistem,lalu mengumpulkan kebutuhan dalam rancangan aplikasi dan deskripsi aplikasi berdasarkan keinginan klien.

2. Pembuatan

Pembuatan sistem didisain secepat mungkin dan mampu merepresentasikan sudut pandang dari aplikasi yang dibuat berdasarkan dari keperluan yang didata pada bagian pertama,hal ini lalu dijadikan acuan model prototipe.

3. Tinjauan Prototipe

Proses ketiga ketika prototipe selesai pengembangan, lalu klien menimjau prototipe maka selanjutnya digunakan memberikan terperinci mengenai informasi tentang persyaratan sistem aplikasi.Dari proses yang dideskripsikan terus berputar hingga semua kesepakatan tercapai. Prototipe diciptakan untuk mengetahui kebutuhan klien. Dari prototipe diharapkan mampu menciptakan sistem yang lebih efisien, tetapi beberapa prototipe mungkin tidak dapat digunakan. Meskipun begitu prototipe memberikan kemudahan hubungan antara pengembang dan pemakai, dengan harapan client mempunyai pandangaan tentang rancangan yang akan dibuat.

\section{HASIL DAN PEMBAHASAN}

\subsection{Gambaran Desain Awal}

Dalam perancangan sebuah website E-Commerce yang memakai rekomendasi menggunakan Algoritma Apriori diperlukan gambaran model sistem,dimana penulis menggunakan diagram UML untuk landasan, salah satunya adalah diagram desain berbentuk use case diagram untuk menggambarkan hubungan yang terbentuk didalam E-Market. 
ISSN 2614-5278 (media cetak), ISSN 2548-8368 (media online)

Available Online at https://ejurnal.stmik-budidarma.ac.id/index.php/mib DOI 10.30865/mib.v5i3.3091

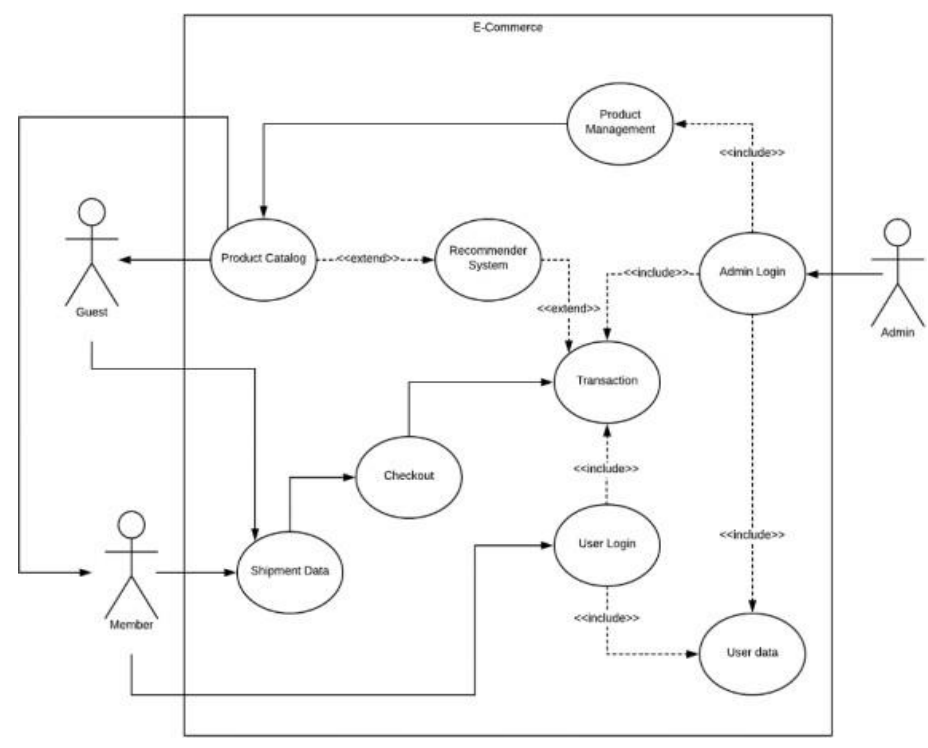

Gambar 2. Use Case Diagram

\subsection{Perancangan Basis Data}

Digunakan dalam rangka memberi kejelasan diantara tiap bagian dasar data yang memeliki keterkaitan antara satu bagian dengan bagian yang lain

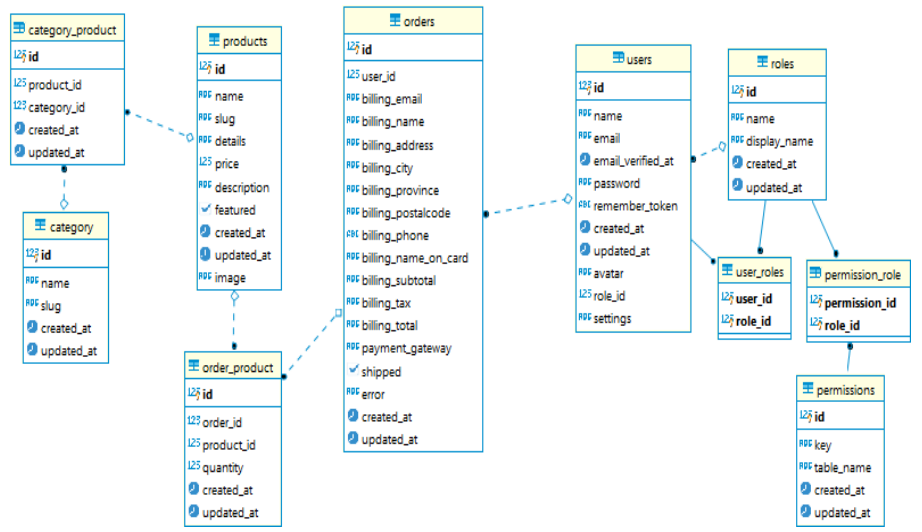

Gambar 3. Rancangan Basis Data

\subsection{Cara Kerja Algoritma Apriori Sebagai Sistem Rekomendasi}

\section{a. Pengumpulan Data}

Diawali dari pendataan terkait pola transaksi pembeli pada penjualan .Kemudian data terkait pwnjualan akan diciptakan pempolaan asosiasi pada data riwayat jual dari pengakses online shop untuk mencari keterkaitan asosiasi dari kombinasi barang yang telah terjual.Dengan cara prmodelan hitungan memakai proses pembuatan nilai support dan nilai confidence didasari hubungan antar barang.Sebuah aturan asosiasi dianggap baik jikalau nilai support lebih daripada nilai minimum support, dan nilai confidence lebih daripada nilai minimum confidence. Teknik apriori digunakan jika ditemukannya hubungan antar barang yang lalu dianalisa.Uji dari proses data mining kemudian mendapat keluaran rekomendasi produk yang cocok dengan barang terkait.Penulis menggunakan data transaksi yang daimbil pada rentan waktu 1 oktober 2020 sampai dengan 12 oktober 2020.

Tabel 1. Pola Transaksi Yang Didapatkan

\begin{tabular}{cl}
\hline Transaksi & \multicolumn{1}{c}{ Pola Transaksi } \\
\hline 1 & Ventela, Vans, Brodo, Adidas \\
2 & Patrobas, Ventela, Dragonfly, Compass.Vans \\
3 & Vans,Converse, Adidas \\
4 & Dragonfly, Brodo, Adidas, Ventela \\
5 & Converse, Adidas, Patrobas \\
6 & Compass, Ventela, Brodo,Vans \\
7 & Patrobass, Dragonfly, Adidas \\
\hline
\end{tabular}


JURNAL MEDIA INFORMATIKA BUDIDARMA

Volume 5, Nomor 3, Juli 2021, Page 1173-1178

ISSN 2614-5278 (media cetak), ISSN 2548-8368 (media online)

Available Online at https://ejurnal.stmik-budidarma.ac.id/index.php/mib

DOI 10.30865/mib.v5i3.3091

\begin{tabular}{cl}
\hline Transaksi & \\
\hline 8 & Adidas, Converse, Vans \\
9 & Brodo, Vans, Compass \\
10 & Ventela, Adidas, Converse \\
11 & Compass, Adidas, Brodo \\
12 & Brodo, Ventela, Compass, Adidas \\
\hline
\end{tabular}

\section{b. Model Teknik Apriori}

Bagian berikut dipakai dalam rangka guna4 mendapat kombinasi barang memakai bentuk frekuensi berdasarkan data penjualan.

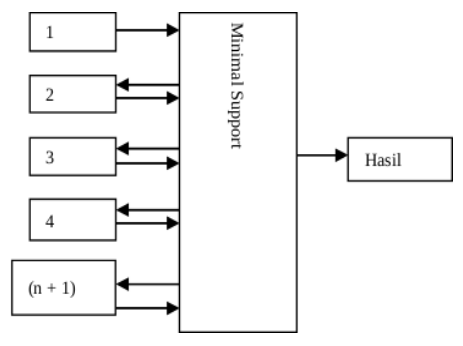

Gambar 4. Proses Kombinasi

Menunjukkan algoritma apriori di mana proses berlanjut apabila suatu data mampu untuk pembentukan itemset selanjutnta. Jika tidak ada kemungkinan maka proses bisa langsung memberikan hasilnya. penulis menentukan nilai support dan nilai confidence sebesar:

1. Minimun support $=3 \%$

2. Minimum confidence:3\%

Dengan penjelasan support A sama dengan transaksi mengandung item A dibagi dengan jumlah transaksi dikali $100 \%$.

\section{c. Pembentukan Item Set}

Setelah mengetahui data dan telah menentukan minimum supportnya maka bisa bisa dilakukan prhitungan untuk mengetahui nilai support dimanaitem yang tidak memenuhi nilai minimum support akan dihilagkan dari list berikut tabel hasil perhitungan.

Tabel 2. Nilai support 1 itemset

\begin{tabular}{lrr}
\hline \multicolumn{1}{r}{ Item } & Jumlah & Support \\
\hline Ventela & 6 & $50 \%$ \\
Vans & 5 & $41 \%$ \\
Brodo & 6 & $50 \%$ \\
Adidas & 9 & $75 \%$ \\
Dragonfly & 3 & $25 \%$ \\
Converse & 4 & $33 \%$ \\
Compas & 4 & $33 \%$ \\
\hline
\end{tabular}

Tabel 3. Nilai support 2 itemset

\begin{tabular}{lrr}
\hline \multicolumn{1}{c}{ Item } & Jumlah & Support \\
\hline Ventela, Brodo & 4 & $33 \%$ \\
Ventela, Adidas & 4 & $33 \%$ \\
Vans, Brodo & 3 & $25 \%$ \\
Vans, Adidas & 3 & $25 \%$ \\
Brodo, Adidas & 4 & $33 \%$ \\
Brodo, Compass & 4 & $33 \%$ \\
Adidas, Converse & 4 & $33 \%$ \\
\hline
\end{tabular}

Tabel 4. Nilai support 3 itemset

\begin{tabular}{crr}
\hline Item & Jumlah & Support \\
\hline Ventela, Brodo. Adidas & 3 & $25 \%$ \\
\hline
\end{tabular}




\section{d. Pembentukam peraturan asosasi}

Bagian terakhir adalah membuat kaidah asosiasi ketika pola frekuensi telah diperoleh.kemudian bagian berikut harus didapatkan peraturan asosiasi harus melampaui kritera paling rendah dari nilai confidence berdasarkan hitungan confidence aturan asosiasi $\mathrm{A} \rightarrow \mathrm{B}$. Dengan aturan minimum Confidence $=3 \%$, Confidence pada $\mathrm{A} \rightarrow \mathrm{B}$ didapatkan:

Tabel 5. Hasil aturan asosiasi

\begin{tabular}{cr}
\hline Item & confidence \\
\hline Ventela,Brodo & $66,67 \%$ \\
\hline
\end{tabular}

Dari data diatas penulis hanya menggambil salah satu data nilai confidence yang didapat,yang dimana dideskripsikan apabila konsumen membeli sepatu Ventela maka konsumen kemungkinan membeli sepatu Brodo dengan nilai confidence sebesar $66,67 \%$ yang dimana hasil tersebut akan diimplementasikan pada system rekomendasi Akshara.co yang dimana produk yang bersangkutan akan diletakkan pada etalase web

\subsection{Implementasi Program}

Berikut merupakan hasil program pada website e-commerce dalam menghasilkan data rule dengan menerapkan algoritma Apriori.

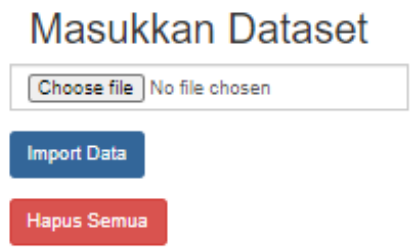

Gambar 4. Menu input data untuk apriori

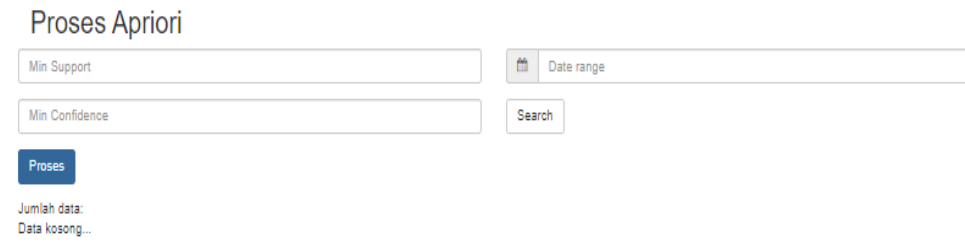

Gambar 5. Input Perhitungan Apriori

Setelah data set di import maka akan menghasilkan rule seperti yang terlihat pada gambar 6 berikut.

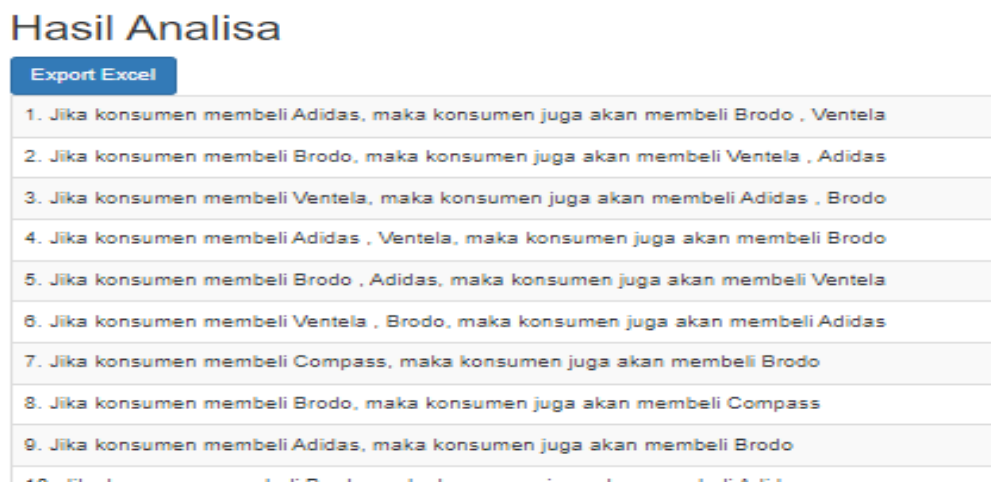

Gambar 6. Hasil rule perhitungan apriori

\section{KESIMPULAN}

Kesimpulan yang didapatkan berdasar dari penelitian yang penulis lakukan bahwa penggunaan algoritma apriori dalam rangka untuk mendapatkan keterkaitan antar barang pada hasil penjualan untuk dijadikan dasar ditemukanya pola asosiasi pada kombiansai antar barang. Pemakaian algoritma apriori dapat menciptakan perekomendasian barang pada e-market berdasarkan persentase conffidence dari kombinasi jenis barang 
ISSN 2614-5278 (media cetak), ISSN 2548-8368 (media online)

Available Online at https://ejurnal.stmik-budidarma.ac.id/index.php/mib DOI 10.30865/mib.v5i3.3091

yang dibeli konsumen, sehingga pemilik dapat menata etalasae sesuai produk yang diminati pada kurun waktu tertentu dalam rekomendasi produk

\section{REFERENCES}

[1] R. Amelia and D. P. Utomo, "ANALISA POLA PEMESANAN PRODUK MODERN TRADE INDEPENDENT DENGAN MENEREPAKAN ALGORITMA FP. GROWTH (STUDI KASUS: PT. ADAM DANI LESTARI),” KOMIK (Konferensi Nas. Teknol. Inf. dan Komputer), vol. 3, no. 1, pp. 416-423, 2019.

[2] B. S. Pranata and D. P. Utomo, "Penerapan Data Mining Algoritma FP-Growth Untuk Persediaan Sparepart Pada Bengkel Motor (Study Kasus Bengkel Sinar Service)," Bull. Inf. Technol., vol. 1, no. 2, pp. 83-91, 2020.

[3] S. J. Tamba and E. Bu, "Implementasi Algoritma Apriori Pada Sistem Persediaan Buah-Buahan ( Studi Kasus : Lotte Mart Wholesale Medan )," J. Pelita Inform., vol. 18, pp. 616-621, 2019.

[4] A. Syarifudin, "Perancangan Sistem Informasi Pengajuan dan Pelaporan Pembayaran Tunjangan Kinerja Kementerian Keuangan Menggunakan Metode Prototype,” J. Sisfokom (Sistem Inf. dan Komputer), vol. 8, no. 2, p. 149, 2019, doi: 10.32736/sisfokom.v8i2.641.

[5] F. Susanto, "Sistem informasi pengolahan data pasien pada puskesmas abung pekurun menggunakan metode prototype," J. Mikrotik, vol. 8, no. 1, pp. 65-73, 2018, [Online]. Available: https://ojs.ummetro.ac.id/index.php/mikrotik/article/view/751/552.

[6] W. Nugraha et al., "Penerapan Metode Protoype Dalam Perancangan Sistem Informasi Perhitungan Volume dan Cost Penjualan," vol. 03, no. 02, pp. 97-105, 2018.

[7] Siswidiyanto, A. Munif, D. Wijayanti, and E. Haryadi, "Sistem Informasi Penyewaan Rumah Kontrakan Berbasis Web Dengan Menggunakan Metode Prototype," J. Interkom, vol. 15, no. 1, pp. 18-25, 2020, doi: 10.35969/interkom.v15i1.67.

[8] H. I. T. Simamora, "Perancangan Sistem Informasi Penjualan Cv Mitra Tani Menggunakan Metode Prototype," JURTEKSI (Jurnal Teknol. dan Sist. Informasi), vol. 6, no. 2, pp. 173-178, 2020, doi: 10.33330/jurteksi.v6i2.552.

[9] A. Rokhim, M. A. Rizki, and T. Informatika, "PENERAPAN METODE PROTOTYPE PADA APLIKASI PENJADWALAN," vol. 13, no. 01, pp. 1-8, 2021.

[10] S. Paembonan and K. Palopo, "Penerapan Metode Prototype Pada Pengembangan Sistem Informasi Kepegawaian Di Dinas Kesehatan Palopo," Mustek Anim Ha, vol. 9, no. 2, 2020.

[11] R. Dwi Asworowati, D. Wijayanti, and Y. K. Ananta, "Sistem Informasi Penerimaan Pengemudi Berbasis Web Dengan Metode Prototype : Studi kasus PT. Dinamika Makmur Sentosa Cikarang," IJCIT (Indonesian J. Comput. Inf. Technol., vol. 3, no. 2, p. 177, 2018.

[12] E. Kurniawan and A. K. Syahputra, "Perancangan Aplikasi Pemesanan Dan Pembayaran Berbasis Desktop Pada Percetakan UD. AZKA GEMILANG Menggunakan Metode Prototype,” Semin. Nas. Raya, vol. 9986, no. September, pp. 105-110, 2018.

[13] D. P. Utomo and B. Purba, "Penerapan Datamining pada Data Gempa Bumi Terhadap Potensi Tsunami di Indonesia," Pros. Semin. Nas. Ris. Inf. Sci., vol. 1, no. 1, pp. 846-853, 2019.

[14] D. P. Utomo, P. Sirait, and R. Yunis, "Reduksi Atribut Pada Dataset Penyakit Jantung dan Klasifikasi Menggunakan Algoritma C5. 0,” J. Media Inform. Budidarma, vol. 4, no. 4, pp. 994-1006, 2020, doi: 10.30865/mib.v4i4.2355.

[15] N. Silalahi, "Penerapan Data Mining Dalam Prediksi Penjualan Prabot Rumah Tangga Menggunakan Metode Apriori Pada Toko Hasanah Mart,” Build. Informatics, Technol. sicience, vol. 2, no. 1, pp. 33-38, 2020.

[16] N. Zamasi, H. Nelly Astuti, and Suginam, "Penerapan Algoritma C 5 . 0 Dalam Analisa Data Potensi Pertanian dan Perternakan ( Studi Kasus : Unit Pembinaan Perlindungan Tanaman," vol. 1, no. 2, pp. 85-90, 2021.

[17] C. V. Purba and E. Buulolo, "Implementasi Algoritma Apriori Untuk Menentukan Pola Data Penyakit Pada Anak Usia Dini (Studi Kasus: RS. Estomihi)," JURIKOM (Jurnal Ris. Komputer), vol. 7, no. 2, p. 308, 2020, doi: 10.30865/jurikom.v7i2.2113. 